\title{
Theoretical Fashions in Crowdsourcing: A Snapshot of IS Research
}

\author{
Abhishek Tripathi \\ The College of New Jersey \\ tripatha@tcnj.edu
}

\author{
Nargess Tahmasbi \\ University of Tampa \\ ntahmasbi@ut.edu
}

\author{
Gert-Jan de Vreede \\ University of South Florida \\ gdevreede@usf.edu
}

\begin{abstract}
When new information technologies emerge, they stimulate the curiosity of Information System (IS) research and practice. Research and practices regarding emerging technologies can be characterized as IS fashions, which can lead to IS innovations. Yet, researchers and practitioners often wonder if these fashions are the next big thing or just a passing fad. One way to determine the contribution of a scientific fashion is to understand its theoretical state and maturity as reported in the literature. We performed a theoretical assessment of one specific IS fashion: crowdsourcing. The main objective of our research is to understand the characteristics of theories in crowdsourcing research and to determine the origins of these theories. Using Gregor's (2006) taxonomy, we performed a systematic literature review to identify and categorize the type of theories developed and used in crowdsourcing research. Close to forty percent of the surveyed articles are explanatory in nature, focusing on cause and effects relationships. Most articles use established theories to motivate research questions or hypotheses. Least common is theoretical research to motivate the design of crowdsourcing related artifacts.
\end{abstract}

\section{Introduction and Motivation}

New information technologies emerge constantly and stimulate the curiosity of Information System (IS) research and practice. Baskerville and Myers have argued that research and practice related to these emerging technologies can be characterized by fashions [1]. IS fashions are defined as a relatively transitory collective belief in IS research and practice, enabled by fashion setters, that a technique or technology leads to rational IS innovation [1]. Whenever managers and research practitioners are confronted with a new fashion (technology), they question whether these fashions are the next big thing or whether it is just passing fad [2]. One way to measure the state and progression of the fashion is to count the number of articles that address it [2]. Most importantly, the challenge for researchers is to structure knowledge and insights about the fashion in such a way that even after initial enthusiasm fades away, organizations can still meaningfully adopt and assimilate the new technologies into everyday work practice [2].

One way to measure the contribution of research in structuring knowledge about the fashion is to understand its theoretical state and maturity. "Having a theory" shows the seriousness and respects to the field. Use of the theory by researchers is the hallmark of their discipline's academic maturity [3, 4]. In this sense, the IS field has progressed significantly in a short span of time. There are researchers that argue that the IS field can be considered a reference discipline [5]. Some IS journals (such as MISQ) and conferences (such as ICIS) are mature enough that their reputation is widely accepted in other fields. Publications in these journals are often a requirement or, at a minimum, a significant boost for the tenure and other achievements in various universities. Regardless of the perceived maturity, several IS researchers have called for increased awareness of the role of the theory in the IS field and discipline (see e.g. [6, 7]). In line with Weber's challenge, the aim of this research is to understand the theoretical progress and maturity of an emerging IS fashion, specifically crowdsourcing.

Baskerville \& Myers suggest that the volume of a discourse about a particular fashion can be a proxy measure to identify a fashion [1]. From this perspective, it can be argued that crowdsourcing is an emerging IS fashion. A chorological search in Google scholar for the keyword "crowdsourcing" suggests an exponential increase in the crowdsourcing research and practice since the inception of the term by Howe [8]. Crowdsourcing is a general problem-solving model, mediated by the web-based technologies to tap the wisdom of large number of individuals - the crowd. The problem to be solved is broadcasted via an open call by the problem owner to invite contributions from a large number of individuals. Different components of crowdsourcing have been identified in the literature. These components include the problem, the crowd, the 
crowdsourcing process and evaluation, problem owners, and the tool or technology [9, 10, 11]. The problem owner can be public/private organizations, government agencies, and individuals. A crowd is generally an undefined large number of diverse individuals. Web 2.0 and other Internet technologies have empowered users with spatial and temporal flexibility. Crowds can participate independently, democratically, and anonymously, at any time and place. An important attribute of crowdsourcing is that it is a collaborative effort enabled by people-centric technology. The core of the crowdsourcing concept originated from the notion that the wisdom of a crowd may be better than solutions created by few specialists or small groups $[12,13]$.

The crowdsourcing business model can be applied to solve various types of problems. Some prominent examples include design (threadless.com, 99design), research and development (InnoCentive), knowledge accumulation for business (Amazon), and fund money for innovative ideas (IBM global entrepreneur). A crowdsourcing business model benefits organizations by providing relatively cheap labor and by tapping geographically and experientially dispersed crowds.

Although the crowdsourcing phenomenon is still in a nascent phase, its core elements - problem owners, crowds, and technology - are historically well represented in IS research. However, crowdsourcing introduces new perspectives and dimensions to these elements, and so may demand integrated or more imaginative views of our traditional understandings and theoretical conceptualizations. It is therefore vital that IS researchers pursue a deeper understanding of the current status of theoretical conceptualizations and contributions so we may better assist in analyzing the social and technical challenges and complexities it introduces [14].

A discussion regarding issues of theory in crowdsourcing (IS fashion) must be structured not only on an understanding of what a theory is and how it can be useful, but also on an understanding of the actual use of theories by crowdsourcing researchers. The main objective of the research reported in this paper is therefore to understand the characteristics of theories in crowdsourcing research and to determine the origins of these theories.

To organize our review, we use Gregor's taxonomy of theory types in IS research. Research in the IS field is concentrated mainly on the interaction between the technology and social systems, and in addition, on the phenomena that emerge in this interaction [6]. Commenting on the different perspectives on theory, Gregor describes theory as an abstract entity that aims to describe, explain, and enhance the understanding of the world, and in some cases, predict outcomes in the future. Theories sometimes also highlight the relation between a cause and effect. Therefore, a theory may have the power of explaining a phenomenon or predicting the phenomenon or its consequences. Gregor proposes a classification scheme for theories in IS which broadly categorizes theories into five major divisions [6]. A summary of the five types is given in Table 1 .

\begin{tabular}{|l|l|}
\hline \multicolumn{2}{|c|}{$\begin{array}{c}\text { Table 1. A Taxonomy of Theory Types in } \\
\text { Information System Research [6] }\end{array}$} \\
\hline Theory Type & Distinguishing Attributes \\
\hline 1. Analysis & $\begin{array}{l}\text { Says what is. The theory does not } \\
\text { extend beyond analysis and } \\
\text { description. No causal } \\
\text { relationships among phenomena } \\
\text { are specified and no predictions } \\
\text { are made. }\end{array}$ \\
\hline 2. Explanation & $\begin{array}{l}\text { Says what is, how, why, when, } \\
\text { and where. The theory provides } \\
\text { explanations but does not aim to } \\
\text { predict with any precision. There } \\
\text { are no testable propositions. }\end{array}$ \\
\hline 3. Prediction & $\begin{array}{l}\text { Says what is and what will be. } \\
\text { The theory provides predictions } \\
\text { and has testable propositions but } \\
\text { does not have well-developed } \\
\text { justificatory causal explanations. }\end{array}$ \\
\hline 5. Design and & $\begin{array}{l}\text { Says what is, how, why, when, } \\
\text { where, and what will be. Provides } \\
\text { predictions and has both testable } \\
\text { propositions and causal } \\
\text { explanations. }\end{array}$ \\
\hline Prediction & $\begin{array}{l}\text { Says how to do something. The } \\
\text { theory gives explicit prescriptions } \\
\text { (e.g., methods, techniques, } \\
\text { principles of form and function) } \\
\text { for constructing an artifact. }\end{array}$ \\
\hline
\end{tabular}

The categorization of existing crowdsourcing theory based on Gregor's taxonomy may help suggesting how existing theoretical research frameworks might be extended to better cover the crowdsourcing arena and give a broader sense of how an emerging IS fashion like crowdsourcing develops. Our research is founded on a structured literature review of top-level IS journals and conference proceedings, expanded to include sources cited by the identified articles. Our findings are important as they clearly demonstrate the increasing interest in the explanation and prediction theory type (type 4) in crowdsourcing within the IS research community. The results provide a valuable snapshot to guide future theory driven crowdsourcing research. 
The remaining sections of this paper details our research method, presents and discusses our findings on the theoretical contributions of published crowdsourcing research, and offers suggestions for future research.

\section{Research method}

Our research employed a foundational literature review as recommended by Webster and Watson [15]. This method is particularly appropriate when examining "an emerging issue that would benefit from exposure" [7], making it particularly applicable to crowdsourcing. Our review began with the major IS conferences (AMCIS, HICSS, ICIS, and ECIS) and the top 11 IS journals: MISQ, ISR, JMIS, JAIS, EJIS, ISJ, JIT, JSIS, CAIS, I\&M, and DSS ${ }^{1}$ [16].

Our literature search ranged from January 2006 through February 2016. The start date was chosen based on introduction of the term 'crowdsourcing' in 2006 [8]. The end date was the most recent literature available. Indexes were first scanned to manually identify potential candidate articles, and then a keyword search for "crowdsourcing", "crowd sourcing", and "collective intelligence" was conducted. Articles selected based on these criteria were then manually screened for applicability. Finally, a Web of Science search on publications cited in these selected articles was conducted, with those articles again screened to select only those truly relevant to crowdsourcing. The articles based on the Web of Science search broadened the scope of literature search and covered a wider range of journals such as MIT's Sloan Management Review, International Journal of Electronic Commerce, Organization Science, CAIM, $J I S$, and 29 other journals. This initial search identified a list of 360 published articles on crowdsourcing. After an in-depth review of these articles, 151 articles were included. Excluded articles either did not aim to theorize on crowdsourcing or were only indirectly related to crowdsourcing.

\section{Analysis Procedures}

For a detailed analysis of the selected research articles, we classified the articles based upon the taxonomy of Theory Types as defined by Gregor [6]. We used the method adopted by [17] for the extraction and identification of theories. We do not exclude the theories on the grounds of their epistemology. We are sampling theory not just from primary explications of theory by the authors, but also from uses of theory in

${ }^{1}$ The list of highly ranked journals and conferences in IS is available on the AIS library website: https://aisnet.org/?JournalRankings articles reporting a certain crowdsourcing phenomena. This implies, for example, that it is necessary to analyze the article discussion sections as well. For this study, a theory is identified if it explicitly mentions the term "theory" or "model" or other grammatical derivative that may explain relationships or evidence of constructs and relationships in an explanation identified by diagrams, words, mathematics, table, or logic. For example, we categorize the article "Getting Inside Your Employees' Heads: Navigating Barriers to Internal-Crowdsourcing for Product and Service Innovation" [18] as "Explanation" theory type based on the following evidence found in the paper (p. 8): "The Internal-Crowdsourcing Acceptance Model is based on the view that internal-crowdsourcing for product/service innovation represents a new business practice that requires a shift in traditional organizational perceptions of value and organizational practices. To make these shifts, requires proactive executive leadership to actively reduce barriers to entry presented by current organizational culture and existing structure."

Two researchers classified the list of articles. Each researcher read the articles and made an initial classification. This classification of articles is based on the quotation from the articles and researcher's own interpretation in accordance with the Gregor's taxonomy of theory types. Any instances where the two researchers classified an article differently were resolved through discussion. Figure 1 shows the frequency of published crowdsourcing articles and their associated theory types. Table 2 shows the use of various theories in crowdsourcing along with the reference discipline of the theory and classification of the surveyed article based on Gregor's taxonomy.

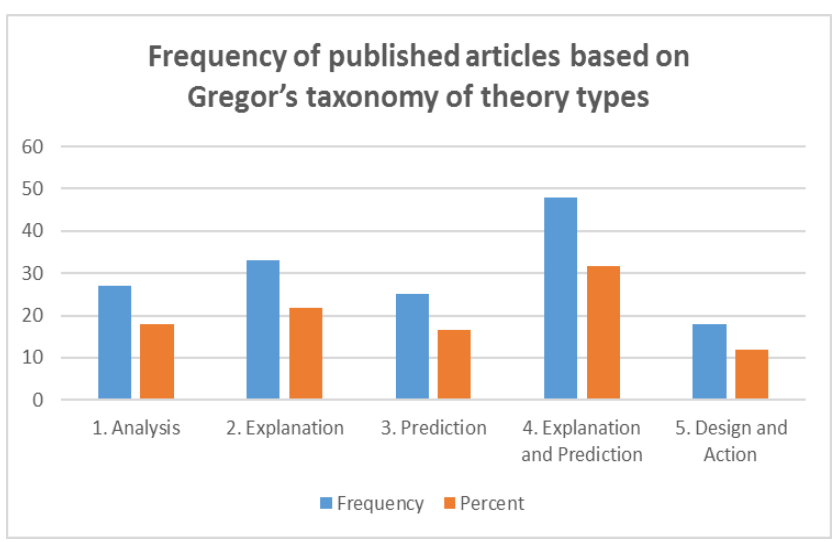

Figure 1. Frequency of published articles based on Gregor's taxonomy of theory types 


\begin{tabular}{|c|c|c|c|c|}
\hline Theory Used & Theory Type & Purpose & Reference Discipline & Theory used in \\
\hline $\begin{array}{l}\text { System } \\
\text { Theory }\end{array}$ & $\begin{array}{l}\text { 5. Design and } \\
\text { Action }\end{array}$ & $\begin{array}{l}\text { Categorization of } \\
\text { crowdsourcing system and } \\
\text { prescription for design of } \\
\text { system }\end{array}$ & Interdisciplinary & [19] \\
\hline $\begin{array}{l}\text { Information } \\
\text { Model }\end{array}$ & 2. Explanation & $\begin{array}{l}\text { To describe the } \\
\text { characteristics of social } \\
\text { commerce }\end{array}$ & Information Systems & {$[20]$} \\
\hline $\begin{array}{l}\text { Five factor } \\
\text { model or } \\
\text { Big Five of } \\
\text { personality }\end{array}$ & $\begin{array}{l}\text { 4. Explanation and } \\
\text { Prediction }\end{array}$ & $\begin{array}{l}\text { Motivations for participation } \\
\text { in online communities varied } \\
\text { according to personality type }\end{array}$ & Psychology & {$[21]$} \\
\hline $\begin{array}{l}\text { Commitment } \\
\text { Theory }\end{array}$ & $\begin{array}{l}\text { 4. Explanation and } \\
\text { Prediction }\end{array}$ & $\begin{array}{l}\text { Theorizing of how each form } \\
\text { of member commitment } \\
\text { relates to different kinds of } \\
\text { online behaviors. }\end{array}$ & $\begin{array}{l}\text { Psychology and } \\
\text { Management }\end{array}$ & {$[22]$} \\
\hline $\begin{array}{l}\text { Self } \\
\text { Determination } \\
\text { Theory }\end{array}$ & 2. Explanation & $\begin{array}{l}\text { Motivation for participation } \\
\text { in crowdsourcing }\end{array}$ & Psychology & {$[23,24]$} \\
\hline $\begin{array}{l}\text { User } \\
\text { Gratification } \\
\text { Theory }\end{array}$ & 2. Explanation & Motivation for participation & Communication & [25] \\
\hline $\begin{array}{l}\text { Motive } \\
\text { incentive- } \\
\text { activation- } \\
\text { behavior } \\
\text { (MIAB) model }\end{array}$ & $\begin{array}{l}\text { 5. Design and } \\
\text { Action }\end{array}$ & $\begin{array}{l}\text { How to design and } \\
\text { implement the ERP software } \\
\text { for the activation } \\
\text { functionality in an idea based } \\
\text { competitions }\end{array}$ & Social Psychology & [26] \\
\hline $\begin{array}{l}\text { Software } \\
\text { platform and } \\
\text { Ecosystems } \\
\text { Theory }\end{array}$ & 2. Explanation & $\begin{array}{l}\text { Evaluation framework for } \\
\text { social media exploitation }\end{array}$ & Software Development & [27] \\
\hline $\begin{array}{l}\text { Theory of } \\
\text { structured } \\
\text { imagination }\end{array}$ & 3. Prediction & $\begin{array}{l}\text { Effect of exposure to an } \\
\text { original or common idea on } \\
\text { crowdsourced idea } \\
\text { generation }\end{array}$ & Cognitive Psychology & [28] \\
\hline $\begin{array}{l}\text { Transaction } \\
\text { Cost Theory }\end{array}$ & $\begin{array}{l}\text { 4. Explanation and } \\
\text { Prediction }\end{array}$ & $\begin{array}{l}\text { Model of workers supplying } \\
\text { labor to paid crowdsourcing } \\
\text { projects (Horton \& Chilton, } \\
\text { 2010); Online sourcing (Lu } \\
\text { \& Hirschheim, 2011) }\end{array}$ & Economics & {$[29,30]$} \\
\hline $\begin{array}{l}\text { Expectancy } \\
\text { theory }\end{array}$ & $\begin{array}{l}\text { 4. Explanation and } \\
\text { Prediction }\end{array}$ & $\begin{array}{l}\text { Predictors of effort } \\
\text { investment in the } \\
\text { crowdsourcing context }\end{array}$ & Management & {$[31,32]$} \\
\hline $\begin{array}{l}\text { Conflict } \\
\text { theory of } \\
\text { decision } \\
\text { making }\end{array}$ & $\begin{array}{l}\text { 4. Explanation and } \\
\text { Prediction }\end{array}$ & $\begin{array}{l}\text { Analyzing effective idea } \\
\text { rating and selection } \\
\text { mechanisms in online } \\
\text { innovation communities }\end{array}$ & Decision Making & {$[33]$} \\
\hline $\begin{array}{l}\text { Uncertainty } \\
\text { theory }\end{array}$ & $\begin{array}{l}\text { 4. Explanation and } \\
\text { Prediction }\end{array}$ & $\begin{array}{l}\text { Service provider pricing for } \\
\text { the service in crowdsourced } \\
\text { market }\end{array}$ & Mathematics & [34] \\
\hline $\begin{array}{l}\text { Theory of } \\
\text { Allocation of } \\
\text { Time }\end{array}$ & 3. Prediction & $\begin{array}{l}\text { Structuring Time through } \\
\text { participation in micro-task } \\
\text { crowdsourcing }\end{array}$ & Economics & {$[35]$} \\
\hline
\end{tabular}




\begin{tabular}{|c|c|c|c|c|}
\hline $\begin{array}{l}\text { Theory of } \\
\text { Legitimate } \\
\text { Peripheral } \\
\text { Participation } \\
\text { (LPP) }\end{array}$ & 2. Explanation & $\begin{array}{l}\text { Motivations for sustained } \\
\text { participation in } \\
\text { crowdsourcing for citizen } \\
\text { science }\end{array}$ & Collaboration & {$[36]$} \\
\hline $\begin{array}{l}\text { Prospect } \\
\text { Theory }\end{array}$ & $\begin{array}{l}\text { 4. Explanation and } \\
\text { Prediction }\end{array}$ & $\begin{array}{l}\text { Participants' Strategy in } \\
\text { Crowd-Based Design } \\
\text { Contests }\end{array}$ & Behavioral economics & [37] \\
\hline $\begin{array}{l}\text { Theory of } \\
\text { Person-Job Fit }\end{array}$ & $\begin{array}{l}\text { 4. Explanation and } \\
\text { Prediction }\end{array}$ & $\begin{array}{l}\text { Criteria that workers use to } \\
\text { choose crowdsourced tasks. }\end{array}$ & Organizational Behavior & [38] \\
\hline $\begin{array}{l}\text { Theory of } \\
\text { Planned } \\
\text { Behavior }\end{array}$ & $\begin{array}{l}\text { 4. Explanation and } \\
\text { Prediction }\end{array}$ & $\begin{array}{l}\text { Participation intention is } \\
\text { positively associated with } \\
\text { actual participation }\end{array}$ & Social Psychology & [39] \\
\hline $\begin{array}{l}\text { Absorptive } \\
\text { Capacity } \\
\text { Theory }\end{array}$ & $\begin{array}{l}\text { 4. Explanation and } \\
\text { Prediction }\end{array}$ & $\begin{array}{l}\text { IT -enabled knowledge } \\
\text { capabilities and firm } \\
\text { innovation }\end{array}$ & $\begin{array}{l}\text { Strategic Management, } \\
\text { Organizational Behavior }\end{array}$ & [40] \\
\hline $\begin{array}{l}\text { Argumentation } \\
\text { theory }\end{array}$ & $\begin{array}{l}\text { 4. Explanation and } \\
\text { Prediction }\end{array}$ & $\begin{array}{l}\text { Decision support for climate } \\
\text { change }\end{array}$ & $\begin{array}{l}\text { Philosophy, } \\
\text { Communication, } \\
\text { Artificial Intelligence }\end{array}$ & [41] \\
\hline $\begin{array}{l}\text { Social Capital } \\
\text { Theory }\end{array}$ & $\begin{array}{l}\text { 4. Explanation and } \\
\text { Prediction }\end{array}$ & Social factors and wiki usage & $\begin{array}{l}\text { Sociology, Political } \\
\text { Science }\end{array}$ & [42] \\
\hline $\begin{array}{l}\text { Democratic } \\
\text { Theory }\end{array}$ & 1. Analysis & $\begin{array}{l}\text { Crowdsourcing as a possible } \\
\text { way to involve the public in } \\
\text { Urban Planning. }\end{array}$ & Political Science & [43] \\
\hline
\end{tabular}

\section{Outcomes and Discussion}

Our analysis of the emergent theoretical foci from crowdsourcing researchers within the context of the Gregor's taxonomy of theory types leads to a number of observations.

The classification results suggest that theory Type 4 (Explanation and Prediction) is most prevalent among the five theory types. Forty-eight articles were classified in this category. The second largest group is Type 2 (Theory for Explanation) with 33 out of 151 followed by Type 1 (Theory for Analysis) and Type 3 (Theory for Prediction) with 33 and 27 out of 151 each. Finally, Type 5 (Theory for Design and Action) was used in the least number of articles (18 out of 151). Articles classified in the theory for Explanation and Prediction type are mostly from top journals such as ISR (6), MISQ (2), Management Science (3), Decision Support Systems (1), JMIS (3), Organization Science (1), MIT Sloan Research paper (1), and top conferences such as ICIS (9), ACM (3) ${ }^{2}$, and AMCIS (7).

As can be seen in table 2, the Explanation and Prediction type theories come from a wide range of

\footnotetext{
${ }^{2}$ Annual Conference on Human Factors in Computing Systems; and Conference on Electronic Commerce
}

established disciplines. These theories from other disciplines have been used either to support or justify the research under investigation or to develop hypotheses.

Articles classified as a Theory of Explanation (Type 2) are mostly from conferences such as ICIS (7) and AMCIS (6) and a few journals such as CAIS (1), CACM (1), Planning theory (1), MIT Sloan management review (1), and JIS (1). Most of the articles classified as this type of theory offer a framework, typologies, or taxonomy to explain crowdsourcing effects and value from various perspectives. For example, [18] proposed a framework developed using grounded theory to explain the strategic use of crowds for organizational needs. Nuttavuthisit proposed a typology of consumers' cocreative practices [44]. [18] proposed an internal crowdsourcing acceptance model, based on the view that internal-crowdsourcing for product/service innovation represents a new business practice that requires proactive executive leadership to actively reduce barriers to entry provided by current organizational culture and existing structure. Brabham, used the self-determination and User Gratification Theory to explain the motivation to participate in crowdsourcing events [18].

Articles classified as a Theory of Prediction (Type 3) also mostly originate from conferences such as ICIS 
(12), HICSS (5), ECIS and AMCIS (4), and a few journals such as JMIS and Management Science (1). For example, [45] used the model of collectivity and generativity from the social sciences to create a theory to make predictions about groups of people with shared interests or goals who mutually engage in rejuvenating, reconfiguring, reframing, and revolutionizing acts. [46] proposed a predictive model to determine an agreeable and adoptable idea. [28] used the theory of structured imagination to study the effect of exposure to an original or common idea on crowdsourced idea generation. [47] combined research on product development processes with research on the economics of contests and tournaments to predict the relationship between the seekers and solvers. [48] use auction theory and propose a game theoretic model of crowdsourcing contests. Finally, [49] describes the rise and fall of crowdsourcing and proposes a proposition to test.

Articles classified as a Theory of Analysis (Type 1) can be found in conferences and journals: conferences such as ICIS (3), HICSS (6), CHI (1) and AMCIS (4), and journals such as CAIM, JAIS, Information Management, ISOLA, Planning theory, and LRP (1). Surveyed articles classified as Analysis type of theory mostly prescribe frameworks, typologies, and taxonomies based on the various attributes of crowdsourcing systems, tasks performed by workers, crowdsourcing applications, motivation of crowds, governance, or general crowdsourcing features. For example, [50] identified the key research areas investigated by the IS researchers and integrated them into an Input-Process-Output model. This framework presents the 'Problem' as the input, the 'Outcome' as the output, and four intervening constructs ('Process', 'Governance', 'Technology', and 'People' (itself broken down into 'owner', 'crowd', and 'individual' sub-categories)) offering their influence in between [14]. [19] proposed a taxonomy of crowdsourcing processes, while [51] proposed a taxonomy based on human computation systems, motivation, quality control, aggregation, human skills, process order, and task-request cardinality.

Articles classified as a Theory of Design and Action (Type 5) are most rare and can be found in conferences such as ICIS (3), HICSS (2), ACIS (1) and AMCIS (2), and journals such as Marketing Science (1), JMIS (3), and Decision Support Systems (1). This type of theory typically offers prescriptions to design IT artifacts. For example, [52] design ranking systems by mining user-generated and crowdsourced content. [19] use a system theory perspective to categorize crowdsourcing systems and discuss how to design such a system.

Figure 1 presents a chronological distribution of theory types in crowdsourcing research. Theoretical contributions started occurring in 2007 as the term "crowdsourcing" was coined by Howe in 2006 [8]. As can be seen, theory-based crowdsourcing research increased significantly between 2007 and February 2016 , with a spike starting in 2009/2010. The count of theory driven articles published in year 2012 was thirty compared to three theory driven articles in year 2007. In 2015 a decline can be observed: seventeen publications compared to 2012's thirty. This may be indicative of what [1] view that IS fashions have "wave-like properties". For each type of phenomenon, there are upswings of interests followed by the precipitous downswings. Data regarding 2016 and beyond is required to confirm this trend. What is also interesting to note is that most of the spike in theory types is of Type II (Explanation) and Type IV (Explanation \& Prediction). Attention for the other theory types has remained fairly constant.

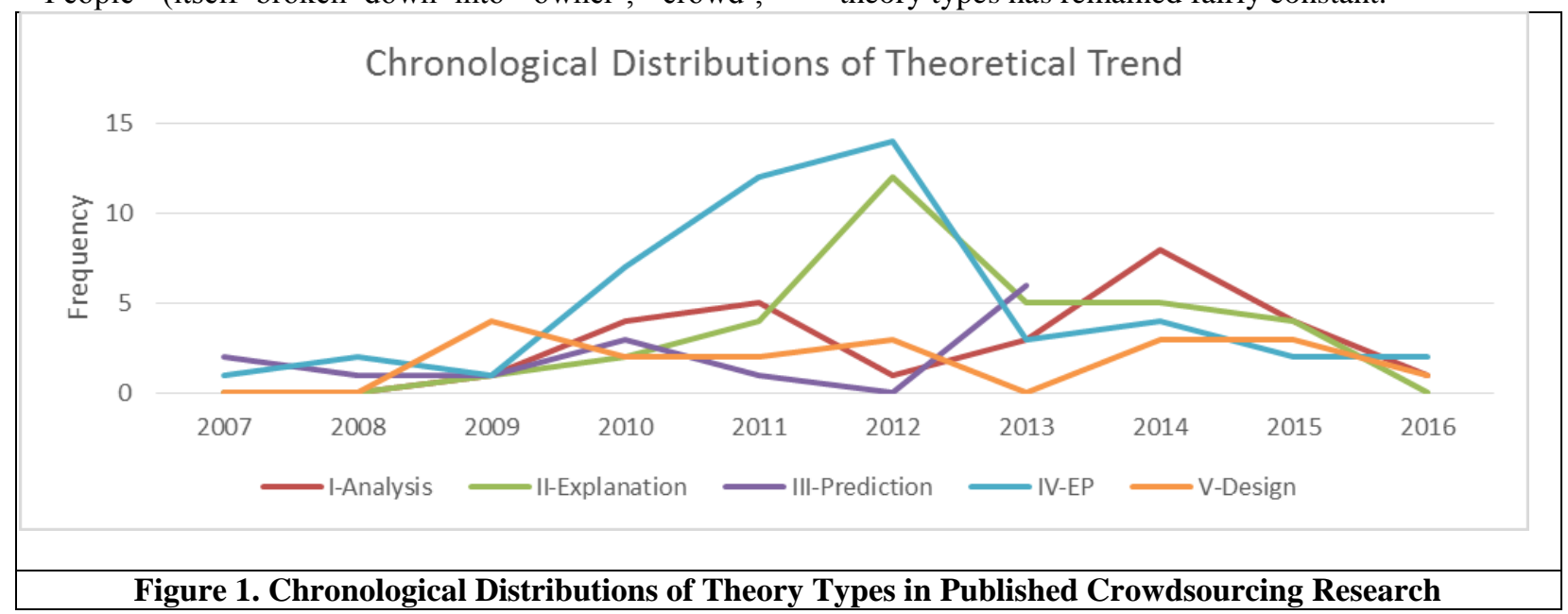


A closer look at the specific theories and models listed in Table 3 shows that along with an increase in the number of theoretical crowdsourcing research publications, the number of unique theories used increases at the same rate. Stated differently, very few theories have been used in more than one article. This may indicate (a) a lack of sharing of theories even within the crowdsourcing research topics, and/or (b) the relative immaturity of the research area where almost each new study contributes a new theoretical perspective to the literature.

To explain and predict various crowdsourcing phenomena, we found that theories have been borrowed from various disciplines. Most of these theories have been used for supporting and motivating a study or to build a hypothesis. However, to advance the field of crowdsourcing research, these theories should also be used to provide a theoretical framework for a study rather than just to support a hypothesis. All five types of theory have in common that they are used as a means of advancing the state of knowledge in a given field - to add to cumulative theory [53]. Based on this notion, we would argue that crowdsourcing research would benefit if researchers used their theoretical efforts to create taxonomies and frameworks as a foundation to develop causal models that explain and predict phenomena.

Furthermore, as technology and its capabilities play an important role in crowdsourcing phenomena, there was surprisingly little theoretical research to prescribe a design and actions (Type 5). This may be partially due to the fact that crowdsourcing is still a relatively new interdisciplinary concept, so many researchers focus on its concepts and applications in the field rather than on prescribing the field how to go about it. Regardless, there is a need to increase this type of research, especially as predictive theoretical research continues to mature.

\section{Conclusions and Future Work}

This structured review investigates the type of theories developed and used in crowdsourcing research. Our findings demonstrate the breadth of interest in crowdsourcing research today. The theoretical research roots of crowdsourcing span across various disciplines such as economics, psychology, organizational behavior, management, and Information Systems. Our observations reveal that close to forty percent of the surveyed articles are explanatory in nature, focusing on cause and effects relationships. Most of the articles use already established theories to justify or motivate research questions or hypotheses. Theoretical research to motivate the design of crowdsourcing related artifacts is least common.
Surveyed articles classified as analysis and explanation types of theory mostly prescribe frameworks, typologies, and taxonomies based on the various attributes of crowdsourcing systems, tasks performed by workers, crowdsourcing applications, collaboration processes, motivation of crowds, governance, or general crowdsourcing features. While crowdsourcing research appears to have a fairly strong theoretical grounding, it is apparent that it still needs to grow its own theoretical roots. Currently, most studies use theories from other disciplines rather than develop their own, new theories. Without sustained efforts to develop its own body of theory, it will be hard for crowdsourcing research to continue to mature and advance as a research area. Having that said, it still seems to be too early to conclude that Crowdsourcing is an IS fashion or a reality. According to the current trend observed in this study, it is safe to say that the future of Crowdsourcing as a mature discipline is promising. The further justification of this claim needs more detailed investigation of the theories that are developed and used in Crowdsourcing not only according to the typology of the theories, but also to the structural component of theories such as constructs, relationships, and boundary conditions. In addition, inclusion of non-theory-driven crowdsourcing studies in our future analysis will further contribute to the justification of this claim.

\section{References}

[1] Baskerville, R. L., \& Myers, M. D. 2009. "Fashion waves in information systems research and practice", MISQ (33:4), pp. 647-662.

[2] Wang, P. 2010. "Chasing the hottest IT: effects of information technology fashion on organizations", MIS quarterly (34:1), pp. 63-85.

[3] Pettigrew, K. E., \& McKechnie, L. E. 2001. "The use of theory in information science research", Journal of the American Society for Information Science and Technology (52:1), pp. 62-73.

[4] Houser, L. 1988. "A conceptual analysis of information science", Library \& information science research (10:1), pp. 3-34

[5] Baskerville, R. L., and Myers, M. D. 2002. "Information Systems as a Reference Discipline”, MISQ (26:1), pp. $1-14$.

[6] Gregor, S. 2006. "The nature of theory in information systems," MISQ (30:3), pp. 611-64.

[7] Weber, R. 2003. "Editor's comment: theoretically speaking”. MISQ (27:3), pp. iii-xii.

[8] Howe, J. 2006. "The Rise of Crowdsourcing," Wired (14:6).

[9] MAD, E., \& ARIM, K. (2012). Crowdsourcing as a tool in conflict prevention. Conflict Trends, 1, 27. 
[10] Chiu, C. M., Liang, T. P., \& Turban, E. (2014). What can crowdsourcing do for decision support? Decision Support Systems, 65, 40-49.

[11] Pedersen, J., Kocsis, D., Tripathi, A., Tarrell, A., Weerakoon, A., Tahmasbi, N., ... \& de Vreede, G. J. (2013, January). Conceptual foundations of crowdsourcing: A review of IS research. In System Sciences (HICSS), 2013 46th Hawaii International Conference on (pp. 579-588). IEEE.

[12] Galton, F. 1907. "Vox Populi”, Nature, 450-451.

[13] Surowiecki, J. 2004. "The wisdom of the crowds", New York, NY: Anchor Books.

[14] Tarrell, A., Tahmasbi, N., Kocsis, D., Tripathi, A., Pedersen, J., Xiong, J., ... \& de Vreede, G. J. 2013. "Crowdsourcing: A Snapshot of Published Research", Proceedings of the 2013 Americas Conference on Information Systems, (14 pages).

[15] Webster, J. and Watson, R. 2002. "Analyzing the past to prepare for the future: writing a literature review," MIS Quarterly (26:2), pp. xiii-xxiii.

[16] Clark, J.G., Au, Y.A., Walz, D.B., and Warren, J. 2011. "Assessing researcher publication productivity in the leading information systems journals: a 2005-2009 update," CAIS (29:1), pp. 459-504.

[17] Hannay, J. E., Sjoberg, D. I., \& Dyba, T. 2007. "A systematic review of theory use in software engineering experiments" Software Engineering, IEEE Transactions on (33:2), pp. 87-107.

[18] Erickson, L. B., Trauth, E. M., \& Petrick, I. 2012. "Getting inside your employees' heads: Navigating barriers to internal-crowdsourcing for product and service innovation proceedings of the 33rd ICIS Orlando, FL, USA, 11 page.

[19] Geiger, D., Rosemann, M. and Fielt, E. 2011. "Crowdsourcing information systems: A systems theory perspective", Proceedings of the 22nd Australasian Conference on Information Systems, Sydney, Australia, Paper 33.

[20] Wang, C., \& Zhang, P. (2012). The evolution of social commerce: The people, management, technology, and information dimensions. Communications of the Association for Information Systems (31:5), pp. 1-23.

[21] Cullen, R. and Morse, S. 2011. "Who's contributing: do personality traits influence the level and type of participation in online communities?" in Proceedings of the 44th HICSS, Computer Society Press, 11 pages.

[22] Bateman, P. J., Gray, P. H., and Butler, B.S. 2011. "The impact of community commitment on participation in online communities," Information Systems Research (22:4), pp. 841-854.

[23] Brabham, D. C. 2012. "Motivations for participation in a crowdsourcing application to improve public engagement in transit planning", Journal of Applied Communication Research, (40:3), pp. 307-328.

[24] Kaufmann, N., Schulze, T., and Veit, D. 2011. "More than fun and money. Worker motivation in crowdsourcing - a study on Mechanical Turk," in Proceedings of the 2011 AMCIS, Paper 340 (12 pages).

[25] Brabham, D.C. 2009. "Crowd sourcing the public participation process for planning projects," Planning Theory (8:3), pp. 242-262.
[26] Leimeister, J. M., Huber, M., Bretschneider, U., and Krcmar, H. 2009. "Leveraging crowdsourcing: activation-supporting components for IT-based ideas competition," JMIS (26:1), pp. 197-224.

[27] Ferro, E., Loukis, E. N., Charalabidis, Y., \& Osella, M. 2013. "Evaluating Advanced Forms of Social Media Use in Government", Proceedings of the 2013 Americas Conference on Information Systems.

[28] Wang, K., Nickerson, J. V., \& Sakamoto, Y. 2013. "Crowdsourced Idea Generation: The Effect of Exposure to an Original Idea", Proceedings of the 2013 Americas Conference on Information Systems, (9 pages).

[29] Horton, J. J., \& Chilton, L. B. 2010. "The labor economics of paid crowdsourcing", In Proceedings of the 11th ACM conference on Electronic commerce (10 pages).

[30] Lu, B.Z. and Hirschheim, R. 2011. "Online sourcing: investigations from service clients' perspective," in Proceedings of the 2011 AMCIS, Paper 405 (15 pages).

[31] Sun, Y., Wang, N., Yin, C. X. and Che, T. 2012. "Investigating the non-linear relationships in the expectancy theory: The case of crowdsourcing marketplace", Proceedings of the 2011 Americas Conference on Information Systems, WA, USA, Paper 6.

[32] Moussawi, S., \& Koufaris, M. 2013. "The Crowd on the Assembly Line: Designing Tasks for a Better Crowdsourcing Experience", Proceedings of the 2013 International Conference on Information Systems, (17 pages).

[33] Riedl, C., Blohm, I., Leimeister, J.M., and Krcmar, H. 2010. "Rating scales for collective intelligence in innovation communities: why quick and easy decision making does not get it right," in Proceedings of the 2010 ICIS, Paper 52 (22 pages).

[34] Hong, Y. and Pavlou, P. 2012. "An empirical investigation on provider pricing in online crowdsourcing markets for IT services", Proceedings of the 33International Conference on Information Systems, Orlando, FL, USA, 16 pages.

[35] Jiang, L., and Wagner, C. 2014. "Structuring Time through Participation in Micro-Task Crowdsourcing: A Time Allocation Perspective," Thirty Fifth International Conference on Information Systems, Auckland.

[36] Jackson, C. B., Osterlund, C., Mugar, G., Hassman, K. D., \& Crowston, K. 2015. "Motivations for sustained participation in crowdsourcing: case studies of citizen science on the role of talk." In System Sciences (HICSS), 2015 48th Hawaii International Conference, (12 pages).

[37] Koh, T.K. 2014. "Participants' Strategy in Crowd-Based Design Contests-a Prospect Theory Perspective," Thirty Fifth International Conference on Information Systems, Auckland.

[38] Schulze, T., Krug, S. and Schader, M. 2012. "Workers' task choice in crowdsourcing and human computation markets", Proceedings of the Thirty Third International Conference on Information Systems, Orlando, FL, USA, (11 pages). 
[39] Zheng, H., Li, D., \& Hou, W. (2011). Task design, motivation, and participation in crowdsourcing contests. International Journal of Electronic Commerce (15:4), pp. 57-88.

[40] Joshi, K. D., Lei, C., Datta, A. and Shu, H. 2010. "Changing the competitive landscape: Continuous innovation through IT-enabled knowledge capabilities", Information Systems Research (21: 3), pp. 472-495.

[41] Iandoli, L., Klein, M., and Zollo, G. 2007. "Can we exploit collective Intelligence for collaborative deliberation? The case of the Climate Change Collaboratorium," MIT Sloan School of Management, Working Paper 4675-08.

[42] Scott, J. E., \& Choi, J. H. 2013. "Wiki Collaboration: Free-riding Students and Relational Social Capital", Proceedings of the 2012 Americas Conference on Information Systems.

[43] Brabham, D.C. 2009. "Crowd sourcing the public participation process for planning projects," Planning Theory (8:3), pp. 242-262.

[44] Nuttavuthisit, K. 2010. "If you can't beat them, let them join: The development of strategies to foster consumers' co-creative practices", Business Horizons, (53: 3), pp. 315-324.

[45] Van Osch, W. and Avital, M. 2010. "Generative collectives," in Proceedings of the 2010 International Conference on Information Systems, Paper 175 (18 pages).

[46] Lee, H., \& Seo, S. (2013, January). What Determines an Agreeable and Adoptable Idea? A Study of User Ideas on MyStarbucksIdea. com. In System Sciences
(HICSS), 2013 46th Hawaii International Conference on (pp. 3207-3217). IEEE.

[47] Terwiesch, C. and Yi, X. 2008. "Innovation contests, open innovation, and multiagent problem solving", Management Science (54: 9), pp. 1529-1543.

[48] Archak, N. and Sundararajan, A. 2009. "Optimal design of crowdsourcing contests," in Proceedings of the 2009 ICIS, Paper 200 (17 pages).

[49] Simula, H. 2013. "The rise and fall of crowdsourcing?", Proceedings of the 46th Annual Hawaii International Conference on System Sciences, Maui, HI, USA, (9 pages).

[50] Pedersen, J., Kocsis, D., Tripathi, A., Tarrell, A., Weerakoon, A., Tahmasbi, N., ... \& De Vreede, G. J. 2013. "Conceptual foundations of crowdsourcing: A review of IS research," in Proceedings of the 46th HICSS, 10 pages.

[51] Quinn, A. J. and Bederson, B. B. 2011. "Human computation: A survey and taxonomy of a growing field", Proceedings of the 2011 annual conference on Human factors in computing systems, ACM, (9 pages).

[52] Ghose, A., Ipeirotis, P. G. and Beibei, L. 2012. "Designing ranking systems for hotels on travel search engines by mining user-generated and crowdsourced content", Marketing Science, (31:3), pp. 493-520.

[53] Truex, D., Holmström, J., \& Keil, M. 2006. "Theorizing in information systems research: A reflexive analysis of the adaptation of theory in information systems research", Journal of the Association for Information Systems (7:12). 